\title{
Trident Replacement and UK Nuclear Deterrence: Requirements in an Uncertain Future
}

\section{Andrew Futter}

To cite this article: Andrew Futter (2015) Trident Replacement and UK Nuclear Deterrence: Requirements in an Uncertain Future, The RUSI Journal, 160:5, 60-67, DOI: 10.1080/03071847.2015.1102548

To link to this article: http://dx.doi.org/10.1080/03071847.2015.1102548 (c) 2015 The Author(s). Published by Taylor \&
Francis.

曲 Published online: 07 Nov 2015.

Submit your article to this journal $\widetilde{6}$

山 Article views: 267

Q View related articles ¿

View Crossmark data $־$ 


\title{
TRIDENT REPLACEMENT AND UK NUCLEAR-DETERRENCE REQUIREMENTS IN AN UNCERTAIN FUTURE
}

\author{
ANDREW FUTTER
}

\begin{abstract}
A decision to replace Trident with a like-for-like system will see the UK remain in the nuclear-weapons business well into the second half of this century, but it is far from clear that reliance on a small, retaliatory nuclear capability for deterrence would be the best approach to an increasingly complex future nuclear-threat landscape. Andrew Futter argues that the requirements of deterrence are perhaps more blurred today than at any point in the nuclear age - a situation only likely to get worse. A more holistic and long-term view of UK nuclear policy is needed, with greater consideration given to how techno-military, strategic and, to a lesser extent, political-normative developments are likely to alter, if not transform, the nature of the future deterrence environment.
\end{abstract}

$\mathrm{T}$ he UK is debating the replacement of its current fleet of four Vanguard-class nuclear-powered submarines (SSBNs) used to carry the Trident nuclear weapons system at a time of great flux, innovation and uncertainty in the global nuclear-deterrence environment. ${ }^{1}$ This emerging strategic context is being shaped by a range of both 'supply-side' and 'demand-side' pressures and dynamics stemming from the development of new, hi-tech military systems and capabilities, a diversification of potential nuclear threats, and an increasingly influential anti-nuclear global political and normative context. While the UK nuclear debate has been lively and heated since the intention to replace the submarines was announced in late $2006,{ }^{2}$ this has focused primarily on the current political and strategic context and particularly on the economic and opportunity costs of retaining nuclear forces - with little apparent thought about what the strategic environment might look like when these new submarines are deployed at the end of the 2020s. ${ }^{3}$ Given that the current UK government will likely agree to move ahead with like-for-like replacement in $2016,{ }^{4}$ and the fact that this decision will see the UK remain part of the exclusive nuclear-weapons 'club' well into the second half of this century, it is essential that some thought be given to whether a limited - albeit sophisticated - retaliatory nuclear weapons system will continue to fulfil UK nuclear deterrence requirements in an uncertain strategic future.

A fundamental guiding principle of the decision to remain in the 'nuclear game' for the next couple of generations has always been the spectre of an uncertain nuclear future, but it appears to be taken as given that UK nuclear weapons - and deterrence through the threat of nuclear retaliation - will remain sufficient in this unknown environment. ${ }^{5}$ As then-Prime Minister Tony Blair pointed out in his foreword to the 2006 White Paper on Trident renewal, 'We believe that an independent British nuclear deterrent is an essential part of our insurance against the uncertainties and risks of the future. ${ }^{6}$ This may well prove to be the case, but a range of developments in recent years suggests that the future operating environment of 2030 and beyond will be far removed from that of today, and especially from that of the Cold War (for which the current system was designed). The key question is whether advances in and the spread of ballistic-missile defences (BMD), improvements in anti-submarine warfare (ASW) capabilities, and the new challenges presented by 'cyber' might mean that UK nuclear weapons are less credible, usable or efficacious in decades to come. This risk of possible nuclear impotence is also being exacerbated by current trends in the international normative and domestic political environment in which policy will be played out - particularly the growing trend of anti-nuclear public sentiment. Taken together, the spread and increasing sophistication of these techno-military 


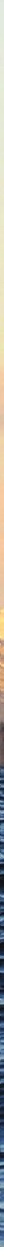

With the current Trident system entering its sunset years, the likely nature of the future nuclear-threat environment must be considered before a decision is made on a possible replacement. Image courtesy Crown Copyright/CPOA(Phot) Tam McDonald.

capabilities, a diversification in the threats that need to be deterred, as well as changing political context might make a policy of 'business as usual' highly problematic - questioning the credibility of UK threats to use nuclear weapons, or even raising the possibility of self-deterrence. While these questions may be for the medium and long term, it would be unwise to exclude them from the debate, thinking and strategy that will underpin the decisions taken about UK nuclear weapons in the near future.

Accordingly, this article proceeds in three sections: first, it provides some background and context to UK nuclearweapons thinking and strategy, before reviewing the current debate about Trident replacement; second, it looks in more detail at the nature of the supplyside military-technical pressures and demand-side strategic, normative and political dynamics transforming and recasting the global nuclear-deterrence environment, and explains the possible implications for the UK; third, it examines three possible future deterrence pathways and begins to outline a framework for a more holistic and longterm view of UK nuclear strategy.

\section{The Nature of the UK Nuclear- Weapons Debate}

The UK joined the exclusive nuclear club in October 1952. Since then, successive UK governments have remained committed to deploying only a limited or minimum nuclear-deterrent capability. After the WE 177 free-fall air-delivered nuclear bomb was retired from service in March 1998, the UK has relied on a fleet of four Vanguard-class submarines armed with Trident submarine-launched ballistic missiles (SLBMs) to deliver its nuclear warheads, and thus undergird its nuclear deterrent. ${ }^{7}$ This fleet of Vanguard-class submarines was first ordered in 1980 became operational in the 1990s and is due to be retired as the service lives of the submarines finish in the 2020s. Given the substantial undertaking required to design, build, test and finally deploy a new fleet of submarines by the time the current ones are retired, the Main Gate decision on whether to push ahead with like-forlike replacement is expected to be taken sometime in 2016. After this, it becomes very unlikely that the replacement programme will be cancelled. ${ }^{8}$

The UK policy of minimum nuclear deterrence is based on retaining the smallest nuclear force required to inflict unacceptable damage on an opponent in order to dissuade it from a nuclear or otherwise potentially existential attack on the UK, or to prevent 'nuclear blackmail'. As the 2006 White Paper put it: ${ }^{9}$

[O]ur focus is preventing nuclear attack. The UK's nuclear weapons are not designed for military use during conflict but instead to deter and prevent nuclear blackmail and acts of aggression against our vital interests that cannot be countered by other means ... The UK will retain only the minimum amount of destructive power required to achieve our deterrence objectives. 
In order to meet this requirement, the UK operates a policy of continuous at-sea deterrence (CASD) whereby one nuclear-armed Vanguard-class submarine is on patrol, hidden under the ocean's surface and ready to fire its nuclear weapons at relatively short notice, at all times. Given the sophistication of the nuclear propulsion systems and other stealthlike technologies, these 15,900-tonne, 150-metre-long boats are virtually undetectable when deployed deep in the ocean and are (currently) viewed as being invulnerable to a pre-emptive disarming strike or other interference, thus ensuring that the UK will always be able to credibly threaten nuclear retaliation. Each Vanguard submarine is capable of carrying up to 192 independently targetable $100 \mathrm{kT}$-class thermonuclear warheads - twelve on each of the sixteen Trident SLBMs although the 2010 Strategic Defence and Security Review (SDSR) limited this to a maximum of eight SLBMs and forty nuclear warheads on each submarine. ${ }^{10}$ The SDSR also reduced the overall nuclear-warhead stockpile to no more than 180 and the operational stockpile from 160 to $120 .{ }^{11}$ This makes the UK one of the smallest nuclear-weapons powers and the only nuclear-armed state to rely on just one delivery system for its nuclear weapons (the Trident SLBMs on the Vanguard submarines).

The decision to begin the process of replacing the current Vanguard fleet has driven a wide and diverse debate, and following the 2010 hung parliament, led directly to the 2013 Trident Alternatives Review (TAR) mandated by the Liberal Democrats as part of their coalition deal with the Conservative Party. The main objective of the TAR was to assess the viability of different options open to the UK beyond like-for-like replacement of the Vanguard-Trident system, and in particular to consider whether there were credible alternatives to using submarines, such as basing weapons on land or deploying them on aircraft; whether other submarine-based options, such as nuclear attack submarines armed with nuclear cruise missiles, might work; and finally whether alternative, reduced or 'relaxed' nuclear postures based on the Vanguard-Trident system were possible. ${ }^{12}$ While the TAR was not a direct statement of government policy, it concluded that like-for-like replacement represented the best and most costeffective option for the UK to meet the future nuclear-deterrence requirements as set out in the 2006 White Paper and 2010 SDSR, although it left open the question of whether three rather than four boats might be required in order to achieve this, or if the policy of CASD might be relaxed. ${ }^{13}$ As a result, and given the outcome of the 2015 general election, the UK government is likely to go ahead and begin building the next generation of nuclear-capable SSBNs in 2016.

\section{Over the past decade the 'Trident renewal' debate has focused on costs}

Over the past decade the 'Trident renewal' debate has focused on costs - particularly opportunity costs for the UK military ${ }^{14}$ and broader UK economy; ${ }^{15}$ the perceived necessity of such weapons in today's post-Cold War, post-9/11 security environment; the implications of Scottish independence; ${ }^{16}$ the UK's commitment to nuclear disarmament under Article $\mathrm{VI}$ of the Nuclear Non-Proliferation Treaty (NPT); and, more recently, the morality and legality of threatening the use of nuclear weapons. ${ }^{17}$ In this way, the debate and therefore the decision to replace the incumbent nuclear system - is very much a reflection of the current political climate, rather than a strategic, long-term assessment not just of what the UK requires for nuclear deterrence, but also whether the existing system will remain as efficacious in a largely unknown and unpredictable future nuclear environment. As the next section explains, it is far from guaranteed that a single submarine armed with a relatively small number of nuclear warheads designed principally for retaliatory strikes will remain sufficient for credible nuclear deterrence in the world of 2030, 2040 and beyond. ${ }^{18}$

\section{Towards a More Diverse Nuclear- Deterrence Environment}

While the current fleet of Vanguard submarines was not deployed until the 1990s, it was conceived, designed and built to reflect the exigencies of the Cold War. This essentially meant retaining the ability to inflict unacceptable damage on the Soviet Union (particularly Russia itself), known colloquially as the 'Moscow criterion', in an environment underpinned by the notion of mutual assured destruction (MAD) through nuclear retaliation. However, this environment has begun to shift in the past two decades - not just because the superpower nuclear standoff has appeared to be replaced with a more complex geopolitical nuclear milieu, but also because of advances in 'supplyside' military-technological tools and capabilities that might be used for deterrence or against nuclear forces, as well as 'demand-side' developments in global normative nuclear thinking regarding what or who needs to be deterred and how. The net result is a global deterrence environment removed from when the current Trident system was first conceived and one that seems likely to become ever-more complex as the deployment of the replacement submarines begins in the late 2020s.

A central principle of UK strategic nuclear thinking appears to be that, in an uncertain future, any actor threatening the use of nuclear weapons against the UK can be deterred through the threat of nuclear retaliation. As the 2006 White Paper argues:19

It is not possible accurately to predict the global security environment over the next 20 to 50 years. On our current analysis, we cannot rule out the risk either that a major direct nuclear threat to the UK's vital interests will re-emerge or that new states will emerge that possess a more limited nuclear capability, but one that could pose a grave threat to our vital interests. Equally there is a risk that some countries might in future seek to sponsor nuclear terrorism from their soil. We must not allow such states to threaten our national security, or to deter us and the international community from taking the 
action required to maintain regional and global security. We can only deter such threats in future through the continued possession of nuclear weapons.

However, and while the nature of the future nuclear-threat environment facing the UK remains unknown (and debated), this does raise key questions about who the UK is trying to deter with its nuclear forces. It is quite possible that different adversaries will require a different mix of capabilities, and even 'tailored deterrence'. It is equally important to consider how this might be achieved in practice, and whether this can remain credible and effective in the long run.

\section{It is quite possible that different adversaries will require 'tailored deterrence'}

A key feature of the last two decades has been a noticeable diversification in the nuclear-threat landscape facing the UK, whereby the traditional focus on large strategic nuclear competitors (such as Russia and, to a lesser extent, China) has been increasingly augmented by a set of new nuclear actors, as part of a transition to a so-called 'second nuclear age'. ${ }^{20}$ In response to these new dynamics, a more diverse US (and NATO) deterrence strategy has already emerged to combat different types of threats: a traditional MAD-based nuclear-centric approach to deal with peer competitors, and a more nuanced strategy including a mixture of offensive and defensive forces to deal with 'rogue' states and possibly non-state nuclear actors that may not 'adhere' to MAD. ${ }^{21}$ However, thus far the UK has remained publicly committed to the efficacy of traditional notions of nuclear deterrence against all potential nuclear threats, even though it remains unclear that a posture based primarily on a retaliatory nuclear force will meet the full spectrum of UK nucleardeterrence demands in the longer term. ${ }^{22}$ This naturally leads to the question of whether deterrence by punishment that is to say, the threat of unacceptable damage caused by a nuclear response can remain the sole basis of UK nucleardeterrence strategy, or whether a more nuanced posture including deterrence by denial (using advanced conventional weaponry for example, either instead of or as well as nuclear forces) might be required to augment this, and help address the wider gamut of potential nuclear threats (including accidents and possible unauthorised use).

The current debate is also premised, consciously or not, on the belief that a small, retaliatory nuclear force will remain highly credible and invulnerable, and that UK policy-makers as well as any potential enemy will be confident that the threat of retaliation can and will be carried out. In fact, a direct knockon effect of the changes described above, and a dynamic likely to impact UK nuclear strategy, is the growth, spread and general acceptance of BMD as a key component of global security thinking. While BMD is primarily a project pursued by the US - a close UK ally - and is theoretically designed to counter the rise of new 'undeterrable actors', such systems are also being developed by a wide variety of other countries too. ${ }^{23}$ While effective anti-SLBM systems remain some way off, the spread of missiledefence capabilities and technology has already caused visible concern about the potential impact on nuclear-deterrent forces in Moscow and particularly in Beijing, ${ }^{24}$ and there is strong reason to believe that such systems will diffuse and be adapted by more actors globally in the future. As Malcolm Chalmers points out: 'US success in deploying effective ballistic missile defences could also, as a result of inevitable technology transfer, increasingly call into question the viability of a deterrent force based on inflicting unacceptable damage with as few as eight ballistic missiles launched from a single submarine'.25 This would in fact present a similar problem to that which faced the UK in the late 1970s following the deployment of the Galosh missiledefence shield around Moscow. ${ }^{26}$ While the Trident-based system - developed in part as a response to Galosh - will very likely be able to overcome any limited defences in the short to medium term, ever-more effective defences may present a growing concern for such a small nuclear force in the long term. This could be a key factor in determining both when and how the UK will need to replace and possibly upgrade its stockpile of nuclear warheads, as well as whether the Trident missile can remain viable until the 2040s as predicted.

\section{Developments in BMD capabilities will be key in determining Trident's future viability}

A further significant aspect of this problem is the possibility that future developments in conventional counterforce technologies, particularly various ASW capabilities, alongside a new suite of dynamics associated with cyber, could bring into question the security and viability of the UK nuclear deterrent - especially in a crisis. Indeed, there is evidence that ASW capabilities are far better than has been generally accepted in the past, and they are only likely to improve in the future. ${ }^{27}$ Likewise, the growth and spread of various cyberweapons and capabilities increase the risk of new vulnerabilities that might be exploited throughout the UK nuclear enterprise, some of which could potentially reduce confidence in the efficacy of the Trident missile system, or might also compromise the invulnerability and stealth of the submarine. ${ }^{28}$ The potential for an adversary of the UK to discover the patrol area of British submarines or the specifics of the boat, missile or warhead through cyberespionage, the possibility of interfering with key systems in the procurement or maintenance phase, or the prospect of lacing targeting or fire-control software with malware, combined with better ASW and BMD capabilities, is clearly a serious issue. A worst-case scenario, therefore, is that at some point in the future the UK could be uncertain that it could hold targets vulnerable with high confidence, that its submarines remained secure and safe against attack, or whether the Trident system had been compromised and would 
work as planned if required. The need to guard against such unforeseen challenges to nuclear platforms is a key reason why both the US and Russia retain a triad of nuclear forces.

\section{The need to guard against unforeseen challenges is why the US and Russia retain a nuclear triad}

Lastly, it is important to contemplate whether the threat of devastating nuclear retaliation (particularly against counter-value targets) will remain credible and viable in an international environment increasingly characterised by anti-nuclear public opinion. Such sentiment has grown considerably over the past decade, both domestically in the UK and internationally through the Global Zero movement, the International Campaign to Abolish Nuclear Weapons, the Humanitarian Initiative and others. While this pressure is unlikely to be decisive in UK decision-making, it does nevertheless appear to be qualitatively different from the nuclear protests of the 1950 s and 1980s. The UK is also the only nuclear-armed state to be fully signed up to the International Court of Justice, which would place a particular burden on nuclear-weapons policy should a ban come into force. ${ }^{29}$ As Philippe Sands and Helen Law point out in their review of the legal aspects of Trident renewal: 'We find it hard to envisage any scenario in which the use of Trident, as currently constituted, could be consistent with the IHL [International Humanitarian Law] prohibitions on indiscriminate attacks and unnecessary suffering. ${ }^{30}$ Given that like-for-like replacement means deterrence by nuclear retaliation (except in the most extraordinary of circumstances ${ }^{31}$ ), it is important to take note of the normative and political environment in which such policies will be acted out and that will form the backdrop for UK nuclear policy and doctrine in the coming decades.

Long-term UK nuclear-deterrence strategy therefore needs to consider three fundamental questions posed by these emerging dynamics: first, whether all types of future nuclear threat to the UK can be or are best deterred primarily through the threat of counter-value nuclear retaliation; second, whether the Vanguard-Trident system will remain invulnerable, reliable and credible in a world where potential UK nuclear adversaries are armed with increasingly sophisticated missile defences, ASW weapons and cyber-capabilities; and third, whether a policy of threatening nuclear mass destruction can remain legal, politically credible and effective in the long run. As explained above, there are good reasons to question all of these assumptions given the changes and developments likely to characterise and reshape the future deterrence environment.

\section{Domestic and international anti- nuclear public opinion has grown considerably over the last decade}

\section{Assessing Options for UK Strategic Deterrence}

Given the questions raised above, it seems sensible and prudent to examine the implications of alternative nuclear futures for the UK and to contemplate different options within a broader and more holistic framework. Accordingly, it makes sense to consider three different possible future pathways: the first, 'business as usual', CASD and retaliatory nuclear deterrence; the second, a blend of nuclear and advanced conventional assets allowing for more diverse deterrence capabilities; and third, a strategy of non-nuclear deterrence. It may well be that the Vanguard-Trident system, CASD and deterrence through the threat of nuclear retaliation remains the best option to meet the UK's longterm strategic requirements (as the TAR concluded), but this should not simply be assumed a priori or other options be excluded from the debate.
The first, and perhaps most likely, option is 'business as usual', whereby the UK government decides to replace the current system with a new fleet of nuclear-capable submarines armed with Trident SLBMs beginning in the late 2020s, giving the UK a nuclear-weapons capability well into the second half of this century. This is likely to involve the retention of CASD and four boats, but it is possible that CASD might be achieved with three submarines, ${ }^{32}$ or that the UK might adopt a more 'relaxed' nuclear posture whereby the one boat is not permanently on station and ready to fire, but could be 'surged' into action if required..$^{33}$ As has been discussed above, there are potentially three main problems with this approach: in the first instance, it is not clear that all future nuclear threats to the UK will be deterrable purely through the threat of nuclear retaliation, or that nuclear counter-force represents a particularly effective or palatable option for UK policy against new nuclear threats; second, the credibility of the UK nuclear deterrent could be compromised by the spread of ever-more effective ballisticmissile defences, various types of cyberattack and interference, or advances in conventional ASW capabilities; and third, the political-normative environment of the future makes the threat and/or use of nuclear forces by the UK less credible. In sum, it is possible that the UK might face a future nuclear threat scenario in which the taboo has been strengthened; traditional adversaries have advanced defences and other capabilities; critical systems might have been compromised; and new nuclear threats are not best addressed through retaliation alone. The 'business as usual' approach is therefore premised - consciously or not - on a belief that international nuclear relations will not change significantly from those that characterised the Cold War, and that Russia and MAD will remain the centrepiece of UK nuclear planning. This approach will also likely involve significant continued investment in modernising and improving UK nuclear forces over the coming decades.

A second option is for the UK to consider a more diverse nuclear and non-nuclear deterrence toolkit, which might include some type of retaliatory 
nuclear weapons system as well as a greater stake in missile defence and an advanced conventional precision-strike capability. This might resemble the 'New Triad' of strategic forces outlined by US President George W Bush in 2002 although it would be much smaller. ${ }^{34}$ The first possibility would be a 'diverse deterrence max' posture, where strategic competitors such as Russia and China would remain at the centre of UK nuclear planning, but moves would be made to address other nuclear concerns as well. This would see the current Trident system renewed, but augmented with new, advanced conventional capabilities. The second option is a 'diverse deterrence lite' posture, which moves away from large nuclear powers being seen as the main nuclear threat and raison d'être for UK nuclear weapons, and focuses instead on new and emerging nuclear challenges. This approach could possibly allow the UK to pursue a reduced nuclear force either fewer submarines, non-continuous patrols, or even some other option as a last resort - while enhancing various advanced conventional deterrence-bydenial capabilities.

\section{The UK might consider playing a greater role in US or NATO BMD}

\section{programmes}

In order to achieve this, the UK might consider a greater role in US and NATO BMD programmes, and perhaps even an indigenous system building on the Fylingdales and Menwith Hill radars. Conceivably, this could involve upgrading the UK's Type 45 destroyers ${ }^{35}$ particularly the Principal Anti-Air Missile System, known as Sea Viper ${ }^{36}$ - for a BMD role, building a new fleet of BMD ships, or even the deployment of a landbased component based on the US Aegis Ashore system planned for deployment in Europe. ${ }^{37}$ The UK could also consider whether advanced conventional precision-strike weaponry could play a counter-force role against specific types of threats in this future environment possibly based on a conventionally armed
Trident D5 missile. Alternatively, the UK could offer to host such weapons for the US and/or as part of a wider NATO policy. Such a mix of forces would allow a more flexible deterrence approach that could be tailored to different types of nuclear challenges, and it would also retain the ultimate threat of nuclear retaliation in extreme circumstances although this would be reduced under a posture of diverse deterrence lite. Diverse deterrence max would be the most comprehensive option for the UK, but would also necessarily be the most expensive. $^{38}$

\section{'Diverse deterrence max' would be the most comprehensive, but most expensive, option}

A final option might be to rely entirely on conventional and advanced conventional weapons for UK strategic deterrence, and therefore to unilaterally disarm for strategic rather than political reasons. This is clearly the most radical option, and would probably have to be based on a military calculation that the 'traditional' Russian nuclear threat should no longer be central to UK planning. That said, the idea has already been raised in a 2014 UK Defence Select Committee report, which noted that 'it is possible to foresee an environment in which the core role of nuclear deterrence - to protect a state from attack - is achieved by the deployment of advanced conventional weapons, providing both offensive and defensive capability'. ${ }^{39}$ A non-nuclear strategic deterrent posture would rely on a mixture of missile and air defences, conventional precision-strike counterforce capabilities as well as an upgraded conventional military. Such a move would clearly have certain political and diplomatic benefits - particularly for the NPT - and could see the UK hailed as a 'disarmament champion' (although the impact of this is debated). ${ }^{40}$ The UK would, presumably, still be covered by the US extended-deterrence umbrella committed to NATO should any serious strategic threat re-emerge that could not be met with conventional forces. Interestingly, a decision in favour of non-nuclear deterrence would not necessarily mean scrapping the next generation of nuclear-powered SSBNs as these could offer a platform for a future UK conventional global promptstrike capability, although this remains a complicated option given the difficulties of discriminating between a nuclear and non-nuclear launch.

\section{Disarming for strategic rather than political reasons would be the most radical option}

\section{Having the Right Debate about UK Nuclear Weapons}

The decision to replace the current fleet of Vanguard submarines, and therefore the UK's nuclear-deterrent capability, has driven a diverse and heated debate, but this discussion has been limited and focused primarily on short-term political and economic dynamics rather than long-term thinking about the requirements of nuclear deterrence. UK nuclear strategy remains based on the assumption - consciously or not - that a small, retaliatory nuclear force capable of deterrence through punishment will be sufficient to meet the nuclear threats of an uncertain future. However, it is increasingly unclear that such a situation will prevail: first, the nature of the possible future nuclear or existential threat to the UK is unlikely to be homogeneous, and may require different tailored approaches and types of deterrence tools; second, it is not clear that such a small deterrent force will remain invulnerable, credible and always able to inflict unacceptable damage in a future environment dominated by sophisticated defences, new vulnerabilities associated with cyber, and advances in ASW technologies; third, it is becoming progressively difficult politically, legally and diplomatically to rely on a policy of inflicting mass casualties through a nuclear strike, and this will call into 
question the credibility of the UK to go through with such threats. Taken together, these dynamics suggest a more diverse and complex future deterrence environment, and one that does not currently appear to feature in the UK nuclear debate. As a result, it is essential that some serious thought be given to who the UK is and will be trying to deter, how these potential threats can be deterred, and with what, and the extent to which this posture can remain credible and efficacious, before embarking on a costly, intrinsically inflexible, multi-decade commitment to the next generation of nuclear weapons.

Andrew Futter is a Senior Lecturer in International Politics at the University of Leicester, UK and currently a Visiting Fellow at the James Martin Center for Nonproliferation Studies in Monterey, California. He is the author of Ballistic Missile Defence and US National Security Policy (Routledge, 2013), The
Politics of Nuclear Weapons (Sage, 2015) and Reassessing the Revolution in Military Affairs (Palgrave Macmillan, 2015). His current research into cyber and nuclear strategy is funded by the Economic and Social Research Council, grant number ES/K008838/1.

The author would like to thank Stephen Ellis, David Jarvis, William Walker, Ben Zala and the anonymous reviewers at RUSI for their thoughts and comments on this piece.

\section{Notes}

1 Trident - or more correctly, Trident II (D5) - is the name of the ballistic missile leased by the UK from the US that 'delivers' UK nuclear warheads to their target, but the term 'Trident' is also often used to refer to the whole UK nuclear system that comprises the Vanguard submarines, the warheads and the associated UK nuclear-weapons infrastructure at Aldermaston, Coulport and Faslane.

2 See Ministry of Defence (MoD) and Foreign Office, 'The Future of the United Kingdom's Nuclear Deterrent', Cm 6994, London, December 2006.

3 The first of the successor submarines is due to be available in 2028 as the first of the current fleet (HMS Vanguard) is nearing retirement. The boats will gradually be replaced one-by-one over the proceeding few years.

4 Despite the election of the anti-Trident Jeremy Corbyn as leader of the Labour Party in September 2015, renewal appears to have strong cross-party support. On this see Matthew Harries, 'Jeremy Corbyn Doesn't Go Nuclear', Survival Editors' Blog, 30 September 2015, <https:// www.iiss.org/en/politics\%20and\%20 strategy/blogsections/2015-932e/ september-dc7b/jeremy-corbyndoesnt-go-nuclear-c56f>, accessed 5 September 2015.

5 As Nick Ritchie explains, 'In an international security environment defined by uncertainty, the certainty of the effectiveness and necessity of nuclear deterrence is largely unexamined in official [UK] discourse'. Nick Ritchie, $A$ Nuclear Weapons Free World? Britain, Trident and the Challenges Ahead (Basingstoke, Palgrave Macmillan: 2012), p. 61.

6 MoD and Foreign Office, 'The Future of the United Kingdom's Nuclear Deterrent', p. 5.

7 For a historical overview of UK nuclear thinking and policy, see John Baylis and Kristan Stoddart, The British Nuclear Experience: The Roles of Beliefs, Culture and Identity (Oxford: Oxford University Press, 2014).

8 Main Gate is when contracts are awarded and production can begin. The Initial Gate decision, taken in 2011, began the process of assessing designs.

9 MoD and Foreign Office, The Future of the United Kingdom's Nuclear Deterrent', p. 17. Emphasis added.

10 HM Government, Securing Britain in an Age of Uncertainty: The Strategic Defence and Security Review, Cm 7948, (London: The Stationery Office, 2010), p. 38.

11 Ibid.

12 HM Government, 'Trident Alternatives Review', 16 July 2013, <https:// www.gov.uk/government/uploads/ system/uploads/attachment_data/
file/212745/20130716_Trident Alternatives_Study.pdf $>$, accessed 5 October 2010.

13 For a good discussion of the pros and cons of CASD see Nick Ritchie and Paul Ingram, 'A Progressive Nuclear Policy: Rethinking Continuous-at-SeaDeterrence', RUSI Journal (Vol. 155, No. 2, April/May 2010), pp. 40-45.

14 As Hugh Beach notes, 'It comes at a time when a number of influential voices, both at home and abroad, are complaining about the hollowing-out of British conventional forces to a point where the UK will cease to be a frontrank ally in the types of operation that actually take place.' Hugh Beach, 'The UK's Nuclear Deterrent: A Response to "The UK's Nuclear Century"', RUSI Journal (Vol. 159, No. 2, April/May 2014), p. 18.

15 See, for example, Kate Hudson, 'A Crisis of Priorities: NHS versus Trident', New Statesman, 15 January 2015.

16 See William Walker, 'Trident's Replacement and the Survival of the United Kingdom', Survival (Vol. 57, No. 5, October/November 2015), pp. 7-28.

17 John Borrie and Tim Caughlet (eds), Viewing Nuclear Weapons through a Humanitarian Lens (Geneva: United Nations Institute for Disarmament Research, 2013).

18 As Malcolm Chalmers points out, 
'Military planners, for their part, appear reluctant to contemplate the possibility of technological developments that could undermine the assumptions on which the UK's strategic force has been based since the 1960s'. Malcolm Chalmers, 'Towards the UK's Nuclear Century', RUSI Journal (Vol. 158, No. 6, December 2013), p. 26.

$19 \mathrm{MoD}$ and Foreign Office, 'The Future of the United Kingdom's Nuclear Deterrent', pp. 6-7. Emphasis added.

20 See Paul Bracken, The Second Nuclear Age: Strategy, Danger and the New Power Politics (New York, NY: St Martin's Press, 2013).

21 As the 2010 US Nuclear Posture Review points out: 'fundamental changes in the international security environment in recent years - including the growth of unrivaled U.S. conventional military capabilities, major improvements in missile defenses, and the easing of Cold War rivalries - enable us to fulfill those objectives at significantly lower nuclear force levels and with reduced reliance on nuclear weapons'. Department of Defense, 'Nuclear Posture Review Report', April 2010, p. v.

22 The Trident system could probably be used in a limited counter-force role against a small nuclear-armed actor or specific target, but it would not, for example, be able to hold all Russian nuclear forces at risk.

23 See, for example, Peter Dombrowski and Catherine Kelleher (eds), Regional Missile Defense from a Global Perspective (Stanford, CA: Stanford University Press, 2015).

24 See Andrew Futter and Benjamin Zala,
'Advanced US Conventional Weapons and Nuclear Disarmament: Why the Obama Plan Won't Work', Nonproliferation Review (Vol. 20, No. 1, 2013), pp. 107-22.

25 Chalmers, 'Towards the UK's Nuclear Century', p. 27.

26 For more on this see Jon Baylis and Kristan Stoddart, 'Britain and the Chevaline Project: The Hidden Nuclear Programme, 1967-82', Journal of Strategic Studies (Vol. 26, No. 4, 2003), pp. 124-55.

27 On this see Austin Long and Brendan Rittenhouse Green, 'Stalking the Secure Second Strike: Intelligence, Counterforce, and Nuclear Strategy', Journal of Strategic Studies (Vol. 38, Nos. 1-2, 2014), pp. 38-73.

28 For a detailed overview of this, see Andrew Futter, 'Hacking the Bomb: Nuclear Weapons in the Cyber Age', paper presented at the International Studies Annual Conference, New Orleans, LA, 23-27 February 2015, <https://www2.le.ac.uk/departments/ politics/people/afutter/copy_of_ AFutterHackingtheBombISAPaper2015 pdf $>$, accessed 5 October 2015.

29 See Eric David, 'The Opinion of the International Court of Justice on the Legality of the Use of Nuclear Weapons', International Review of the Red Cross (Vol. 37, No. 316, 1997), pp. 21-34.

30 Philippe Sands and Helen Law, 'The United Kingdom's Nuclear Deterrent: Current and Future Issues of Legality', Greenpeace, 5 April 2007, <http://www. greenpeace.org.uk/MultimediaFiles/ Live/FullReport/8072.pdf>, accessed 5 October 2010, p. 3.
31 While the UK pledges only to use nuclear weapons defensively, it has not adopted a 'No First Use' posture.

32 On this see Hugh Chalmers, 'A Disturbance in the Force: Debating Continuous At-Sea Deterrence', RUSI Occasional Paper, London, January 2014.

33 See Malcolm Chalmers, 'Continuous AtSea Deterrence: Costs and Alternatives', RUSI Briefing Paper, July 2010.

34 For more on the 'new triad' see David McDonough, Nuclear Superiority: The 'New Triad' and the Evolution of Nuclear Strategy, Adelphi Paper 383 (Abingdon: Routledge for IISS, 2006).

35 See Global Security Newswire, 'UK Navy Considers Giving Warships Missile Defense Role', 12 September 2013.

36 See Andrew Elwell, 'World Class: The UK's Sea Viper Air Missile Defence System', DefencelQ, 23 January 2013.

37 Jon Hudson and Michael Codner, 'Missile Defence Considerations for the United Kingdom', RUSI Journal (Vol. 155, No. 3, June/July 2010), p. 18.

38 That said, the development of advanced conventional systems would presumably offer opportunities for UK industry and research and development too.

39 House of Commons Defence Select Committee, 'Deterrence in the $21^{\text {st }}$ Century', eleventh report, 11 March 2014, paragraph 71.

40 Ritchie, A Nuclear Weapons Free World?, pp. 141-42. 